Special issue in honor of Prof. George C. Papageorgiou

REVIEW

\title{
Intersections: photosynthesis, abiotic stress, and the plant microbiome
}

\author{
B. DEMMIG-ADAMS*,+, S.K. POLUTCHKO*, M.C. ZENIR ${ }^{*}$, P. FOUROUNJIAN**, J.J. STEWART*, \\ M. LÓPEZ-POZO*, and W.W. ADAMS III*
}

Department of Ecology and Evolutionary Biology, University of Colorado, Boulder, CO 80309, USA*

International Lemna Association, Denville, NJ 07834, USA ${ }^{* *}$

\begin{abstract}
Climate change impacts environmental conditions that affect photosynthesis. This review examines the effect of combinations of elevated atmospheric $\mathrm{CO}_{2}$, long photoperiods, and/or unfavorable nitrogen supply. Under moderate stress, perturbed plant source-sink ratio and redox state can be rebalanced but may result in reduced foliar protein content in $\mathrm{C}_{3}$ plants and a higher carbon-to-nitrogen ratio of plant biomass. More severe environmental conditions can trigger pronounced photosynthetic downregulation and impair growth. We comprehensively evaluate available evidence that microbial partners may be able to support plant productivity under challenging environmental conditions by providing (1) nutrients, (2) an additional carbohydrate sink, and (3) regulators of plant metabolism, especially plant redox state. In evaluating the latter mechanism, we note parallels to metabolic control in photosymbioses and microbial regulation of human redox biology.
\end{abstract}

Keywords: carbohydrate; electron transport; homeostasis; nitrogen; reactive oxygen species; redox signaling.

\section{Introduction}

Photosynthesis by natural and agricultural populations of plants and other photosynthetic organisms is the engine for essential services rendered by these systems, including $\mathrm{CO}_{2}$ sequestration and the production of food, fuels, and materials. Photosynthesis is linked to plant growth and development, not only via the supply of energy but also as a source of information about the state of the plant's environment. The processes of photosynthetic light collection and electron transport provide direct input into essential signaling transduction networks with 'profound influence on almost every aspect of plant biology' (Foyer and Noctor 2016).
Climate change affects many environmental inputs that impact photosynthesis (Dusenge et al. 2019, Ainsworth and Long 2021). While both $\mathrm{CO}_{2}$ and light are necessary inputs into photosynthesis, the proverbial 'too much of a good thing' of either or both profoundly alters the metabolic function and can even disrupt plant metabolism. This metabolic disruption is somewhat reminiscent of the metabolic disruption triggered by an overly energydense diet in animals (Gill 1999). Furthermore, today's rising atmospheric $\mathrm{CO}_{2}$ concentrations impact other environmental factors, including indirect effects on light supply. The hotter and drier summers associated with climate change are driving the relocation of some plant communities and agricultural operations to higher, cooler

\section{Highlights}

- Abiotic stress impacts on photosynthesis are comprehensively reviewed

- Abiotic stress combinations disrupt via synergistically acting mechanisms

- The plant microbiome can counter multiple disrupting mechanisms
Received 23 September 2021

Accepted 7 December 2021

Published online 13 January 2022

${ }^{+}$Corresponding author

phone: (303) 492-5541

e-mail: barbara.demmig-adams@colorado.edu

Abbreviations: AOX - alternative oxidase; ROS - reactive oxygen species.

Acknowledgments: This work was supported by the Translational Research Institute for Space Health through Cooperative Agreement NNX16AO69A, National Science Foundation award number IOS-1907338, and the University of Colorado.

Conflict of interest: The authors declare that they have no conflict of interest. 
latitudes, where plants experience longer photoperiods in the summer (Vitt et al. 2010, Hu et al. 2019, CarlsonNilsson et al. 2021, Mølmann et al. 2021). Moreover, the effect of elevated $\mathrm{CO}_{2}$ and/or increased light supply varies depending on yet other environmental factors, such as nitrogen supply. This review comprehensively evaluates the effect of combinations of elevated atmospheric $\mathrm{CO}_{2}$ concentrations, long photoperiods, and/or unfavorable nitrogen supply on photosynthesis, plant growth, and the maintenance of plant redox homeostasis (see Fig. 1).

A high supply of $\mathrm{CO}_{2}$ and/or light can shift the balance between sugar-producing source leaves and sugar-consuming sink tissues (source-sink balance). Carbohydrates backing up in leaves can trigger a sequence of events that alters plant redox balance - a balance between oxidants and antioxidants (Paul and Foyer 2001, Foyer and Noctor 2009, 2020; Demmig-Adams et al. 2018). Plant redox state has a central role in adjusting

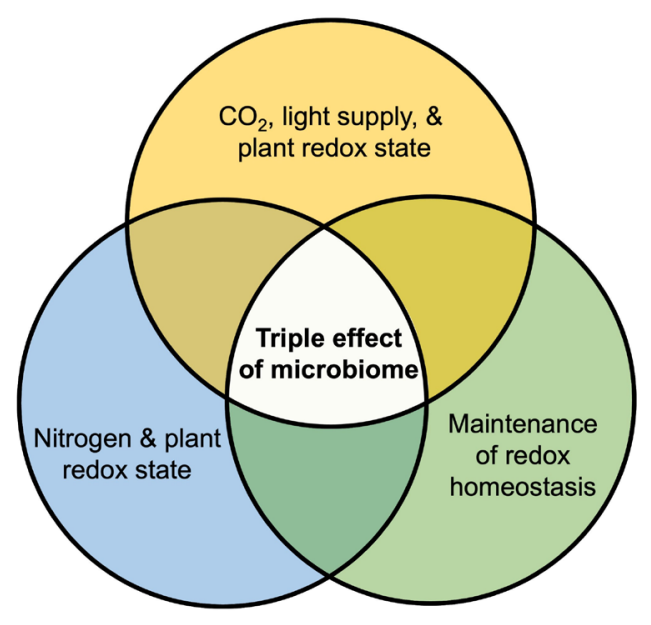

Fig. 1. Schematic depiction of the approach taken in the present review of synthesizing several bodies of literature to identify common themes that provide targets for plant-microbe interaction. The three circles represent the major sections (headers) of this review, and the overlapping area represents the resulting conclusion that the plant microbiome has a triple effect in interacting with each and all of these areas. plant growth, reproduction, and defense throughout plant development and in response to shifts in environmental conditions (Wilson et al. 2006, Zaffagnini et al. 2019). When changes in the environment are moderate, internal signaling networks orchestrate adjustments to maintain growth and rebalance plant source-sink ratio and redox state. However, when environmental conditions are more extreme and exceed the plant's capacity to maintain cellular redox homeostasis, growth rates decline and photosynthesis can be dramatically downregulated (Suzuki et al. 2012, Adams et al. 2013, 2014, 2018; Demmig-Adams et al. 2014). Elevated $\mathrm{CO}_{2}$ concentrations also strongly interact with plant nitrogen metabolism (Tausz-Posch et al. 2020), and both limiting (Agüera and De la Haba 2018) or excessive soil nitrogen supply (Adavi and Sathee 2021a,b) can exacerbate disruption of cellular redox homeostasis.

Plant-microbe interaction may be able to maintain plant productivity over a wider range of challenging environmental conditions (Fig. 2; Chouhan et al. 2021). Our review comprehensively examines the potential of microbial partners to counteract photosynthetic downregulation and metabolic disruption, thereby maintaining plant redox homeostasis both indirectly and directly. The plant microbiome may exert indirect effects on the plant redox state by (1) acting as an additional sugar sink that consumes photosynthetically produced sugars as well as (2) improving plant nitrogen status. Ainsworth et al. (2004) reported photosynthetic downregulation under elevated $\mathrm{CO}_{2}$ in a soybean line that does not form a symbiotic relationship with bacteria, and prevention of such downregulation in a nodule-forming soybean line forming a symbiosis with Rhizobium bacteria that represents a large carbon sink. In addition, microbial manipulation could directly affect plant redox state and the content of reactive oxygen species (ROS). A recent study on the response of mustard (Brassica juncea) to drought conditions reported that rhizobacteria-inoculated $v s$. uninoculated plants exhibited enhanced shoot and root biomass, greater water content, higher rates of photosynthesis, and greater expression of antioxidant enzymes. The study concluded that 'rhizobacteria mediated maintenance of ROS homeostasis' (Asha et al. 2021). We summarize below available evidence from several

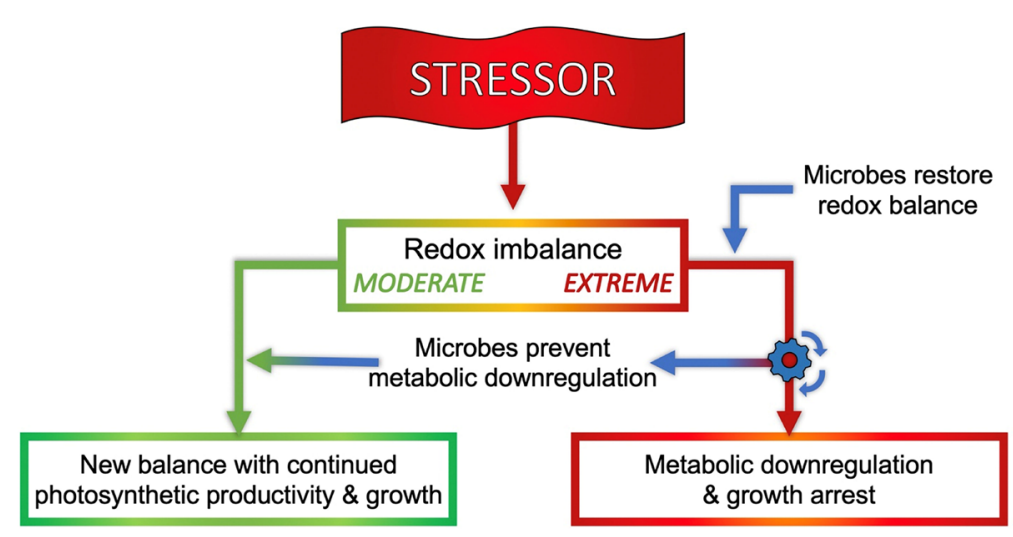

Fig. 2. Schematic depiction of common overarching themes in the effect of environmental stress (stressor) and the plant microbiome. Stressors shift plant redox balance to a degree that is either moderate enough (green boxes) to allow continued productivity or extreme enough (red boxes) to trigger downregulation of growth and metabolism. Also represented is the conclusion from the literature synthesis in this review that the plant microbiome has the potential to restore redox balance and prevent metabolic downregulation (represented by the blue dial and the arrows pointing from the red to the green zone). 
bodies of literature that these microbial effects can support higher plant nitrogen and protein contents under elevated $\mathrm{CO}_{2}$ and maintain plant growth under combinations of unfavorable abiotic conditions in the plant's environment.

\section{Literature synthesis}

Below is a synthesis of evidence from several fields of inquiry, focusing on $\mathrm{CO}_{2}$, light supply, and plant redox state in the context of plant source-sink balance, nitrogen and plant redox state in the context of imbalances in plant nitrogen metabolism, and mechanisms to maintain redox balance in plants, photosymbioses of algae and their hosts, and other host-microbe systems. Integrative evaluation of these bodies of literature is used to identify the plant microbiome as having multiple effects with the potential to restore the balance of source-sink ratio, nitrogen metabolism, and plant redox state (Fig. 1). Since the focus of the current review is the overlap among these other fields, authoritative reviews in each of these areas are cited that provide a more exhaustive summary in each field than can be provided here. Similarly, the schematic diagrams in the present review highlight connections and common themes rather than aiming to provide specific details.

$\mathrm{CO}_{2}$, light supply, and plant redox state: This section discusses the effects of elevated $\mathrm{CO}_{2}$ in the context of plant source-sink balance. Plant photosynthetic capacity (of the sugar-producing source leaves) is controlled by demand from the whole plant (all its sinks) for sugar (Demmig-Adams et al. 2017). Key photosynthetic genes subject to this control by the plant's sugar-consuming sinks include the small subunit of the $\mathrm{CO}_{2}$-fixing enzyme Rubisco, chlorophyll $(a+b)$-binding complexes, and ATP synthase (Krapp and Stitt 1995) as well as others (for a report on the photosystem II reaction center protein D1, see Kilb et al. 1996). Because photosynthesis is controlled by the demand for its products, increased photosynthetic rates under high $\mathrm{CO}_{2}$ can only be sustained when there is continuously high demand for sugars from sinks, i.e., from sugar-consuming and/or storing plant tissues (Kasai 2008) and/or from the plant's microbial partners (Ainsworth et al. 2004; see Adams et al. 2018). Initial increases in photosynthetic rates in response to elevated $\mathrm{CO}_{2}$ are followed by adjustments (acclimation) that can include downregulation of photosynthetic activity [via repression of the small subunit of Rubisco, chlorophyll $(a+b)$-binding complexes, ATP synthase, and others]. Exposure to elevated $\mathrm{CO}_{2}$ causes plants with modest to low sink strength to successively build up carbohydrates in leaves (Ainsworth et al. 2004) or stems (Macabuhay et al. 2018), whereas plants with large carbon sinks show no such backup (Tausz-Posch et al. 2020). Carbohydrate backup in source leaves, in turn, triggers feedback downregulation of sugar production in photosynthesis (Fig. 3). For example, Arabidopsis

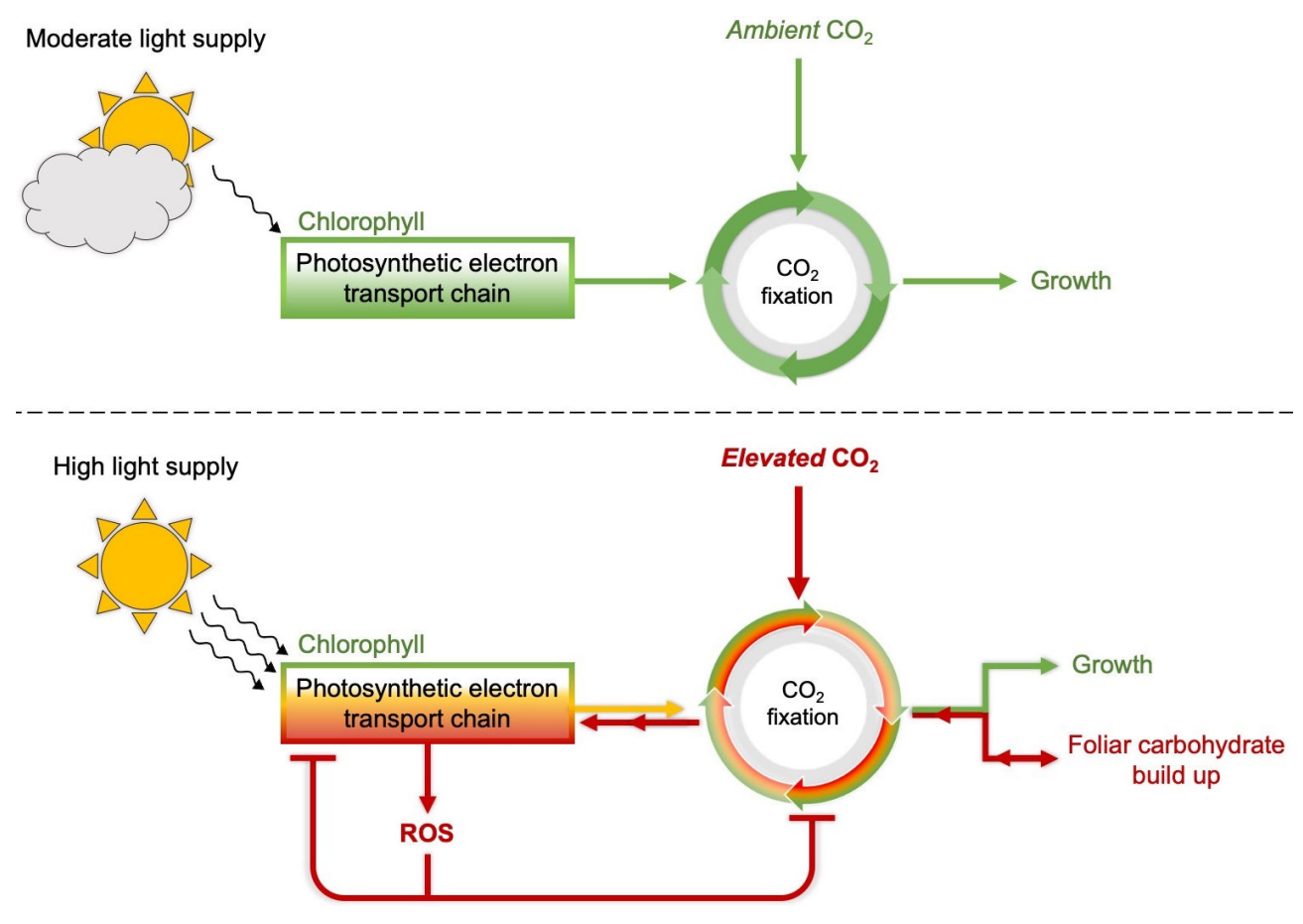

Fig. 3. Schematic depiction of the general principles of how moderate light supply under ambient $\mathrm{CO}_{2}$ (top; green color) or a combination of high light supply and elevated $\mathrm{CO}_{2}$ (bottom; orange to red color) can act on photosynthetic electron transport and $\mathrm{CO}_{2}$ fixation. Red arrows running in the reverse direction, back from $\mathrm{CO}_{2}$ fixation to the photosynthetic electron transport chain, symbolize that elevated $\mathrm{CO}_{2}$ coupled with high light is likely to trigger foliar carbohydrate build-up and backing up of electrons in the photosynthetic electron transport chain. Additional red arrows symbolize formation of excess reactive oxygen species (ROS) in this situation, and repression of photosynthetic genes involved in the light reactions and $\mathrm{CO}_{2}$ fixation. 
thaliana's response to long-term elevated $\mathrm{CO}_{2}$ included downregulation of photosynthetic sugar production and was described as 'metabolic perturbation' (Li et al. 2008).

In conclusion, high levels of photosynthesis were sustained under high $\mathrm{CO}_{2}$ concentrations only when other environmental conditions permitted continuous rapid growth (Yilmaz et al. 2017) or when plant carbohydratestorage capacity was extensive (Aranjuelo et al. 2011), whereas photosynthesis was downregulated when sink activity was limited (Thomas and Strain 1991, Aranjuelo et al. 2005). Significant limitations of plant sink activity, and photosynthetic downregulation, can be imposed by various conditions on their own or in combination (Demmig-Adams et al. 2017, Adams et al. 2018), such as a low supply of nutrients or water (Porras et al. 2017, Wang et al. 2017, Tausz-Posch et al. 2020), restricted root expansion (Andrade et al. 1993, Poorter et al. 2012), or genetic constraints to either fast growth (Poorter et al. 1990) or efficient nitrogen uptake and utilization (Adavi and Sathee 2021a, Padhan et al. 2020). Photosynthetic downregulation is a result of a series of regulatory events, where carbohydrate build-up feeds back into the photosynthetic electron transport chain (Fig. 3). Specifically, when carbohydrates build up in leaves, $\mathrm{CO}_{2}$ fixation consumes the products of photosynthetic electron transport at a lesser rate, which can lead to a transient backup of electrons and transfer of these electrons to oxygen, resulting in the formation of greater ROS amounts (Fig. 3; Demmig-Adams et al. 2014). ROS are regulators of a host of essential genes, and ROS level functions as a means 'to monitor metabolic flux' (Foyer and Noctor 2016), including repression of key photosynthetic genes with roles in the light reactions [e.g., chlorophyll $(a+b)$ binding complexes and ATP synthase] and $\mathrm{CO}_{2}$ fixation (e.g., the small subunit of Rubisco) when sugar production vs. consumption becomes unbalanced (Fig. 3; Foyer and Noctor 2020, Hasanuzzaman et al. 2020). In addition, carbohydrate build-up can also repress photosynthetic genes via sugar-signaling pathways (Roth et al. 2019).

The process of metabolic downregulation can occur with or without accompanying growth penalties. Under moderate stress, such as a combination of elevated $\mathrm{CO}_{2}$ with long hours of high light in an environment otherwise favorable for growth (e.g., favorable nitrogen supply), downregulation of photosynthetic capacity allows $\mathrm{C}_{3}$ plants to support a similar rate of photosynthesis and growth under high $v s$. lower $\mathrm{CO}_{2}$ concentrations, but with lesser investment in the components of the photosynthetic machinery that collect light and fix $\mathrm{CO}_{2}$. This lesser investment lowers foliar protein content (of which the $\mathrm{CO}_{2}$-fixing enzyme Rubisco is a significant portion, particularly in $C_{3}$ plants) and can also lower the protein content of grain (Bahrami et al. 2017). Such adjustment of plant metabolism can thus lower crop nutritional quality for the human consumer as well as the nutritional quality of natural vegetation (nitrogen content, protein, and carbon-to-nitrogen ratio) for the nonhuman consumer, thereby reverberating up into higher trophic levels (Sardans et al. 2012). The combination of high light and high $\mathrm{CO}_{2}$ supply can thus have a cost to the consumer in the form of lower protein concentrations in $\mathrm{C}_{3}$ plants and a higher carbon-to-nitrogen ratio of plant biomass. Combinations of elevated $\mathrm{CO}_{2}$ with environmental conditions that limit growth can enhance photosynthetic downregulation, exacerbate growth reductions, and trigger early senescence (for details, see the following subsections).

It should be noted that engagement of photoprotective measures in their full capacity counteracts metabolic disruption. Such photoprotection includes dissipation of excess excitation energy as heat (Demmig-Adams et al. 2012), rerouting of electrons (Kramer et al. 2004), and elimination of ROS by antioxidant metabolites and/ or enzymes (Havaux and García-Plazaola 2014), all of which counteract the formation or accumulation of ROS. When the capacity of these protective processes is exceeded under severe stress, highly excessive ROS production can shut down photosynthesis in a feedback loop (Adams et al. 2006, 2013, 2014; Demmig-Adams et al. 2014, Foyer 2018). Prins et al. (2009) noted that elevated $\mathrm{CO}_{2}$ can also trigger accelerated leaf senescence when sugars accumulate to concentrations that inhibit photosynthetic gene expression (see Dai et al. 1999, Moore et al. 1999, Diaz et al. 2005).

Nitrogen and plant redox state: Just like excess $\mathrm{CO}_{2}$ and excess light, unbalanced nitrogen metabolism (either limiting or excess nitrogen) can disrupt plant redox balance (Chaput et al. 2020). While nitrogen is required for photosynthesis, the growth of sink tissues is the process that is most sensitive to a shortage of mineral nutrients, especially nitrogen (Burnett et al. 2018). Plant sink tissues require carbohydrates and nitrogen in a balanced ratio, and a shortage of nitrogen leads to a backup of carbohydrates. In some scenarios, a plant's capacity to provide reduced forms of nitrogen for amino acid/protein synthesis decreases under elevated $\mathrm{CO}_{2}$ (Stitt and Krapp 1999, Feng et al. 2015, Foyer and Noctor 2020). One suggestion for how the internal availability of nitrogen for amino acid synthesis may decline under elevated $\mathrm{CO}_{2}$ involves suppression of photorespiration, a process with an important role in the nitrogen metabolism of $\mathrm{C}_{3}$ plants (Bloom 2015, Busch et al. 2018). Another mechanism involves high levels of nitrate supply and the step of nitrate reduction by nitrate reductase. Elevated $\mathrm{CO}_{2}$ concentrations initially stimulate nitrate reductase activity, which is associated with the enhanced production of redox messengers (nitric oxide and ROS; Bian et al. 2020). These messengers can secondarily repress key genes in nitrogen metabolism, including nitrate reductase itself (Wu et al. 2020; see also Shin and Schachtman 2004, Kim et al. 2010), and can trigger plant senescence (Adavi and Sathee 2021a, Padhan et al. 2020; see also Queval et al. 2007, Krasensky-Wrzaczek and Kangasjärvi 2018).

\section{Synergy among environmental factors}

Plants sense the availability of $\mathrm{CO}_{2}$, light, and nitrogen and funnel these environmental inputs into a common master signaling network that orchestrates plant response (Fig. 4). $\mathrm{CO}_{2}$, light, and nitrogen supply are all inputs into 


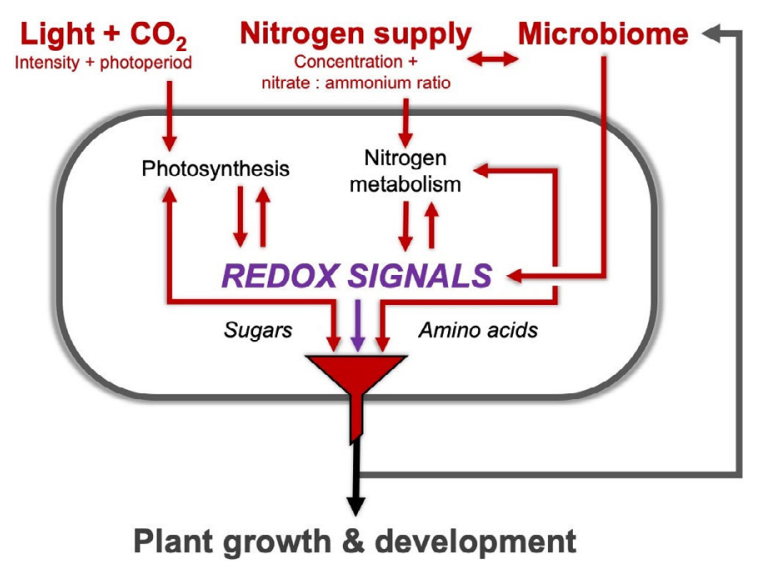

Fig. 4. Schematic depiction of common principles by which signals from environmental inputs of light, $\mathrm{CO}_{2}$, nutrients (total nitrogen supply and nitrate-to-ammonium ratio), and the plant microbiome are integrated into common redox-signaling networks that orchestrate plant growth and development. The black outer arrow pointing back to the microbiome symbolizes the portion of photosynthetically produced sugars that sustain the plant's microbial partners, with the rest supporting the plant's own growth and development.

plant redox state (Fig. 4; Lake et al. 2002, Suzuki et al. 2012, Mhamdi and Noctor 2016) that, in turn, regulates photosynthesis, growth, and multiple other essential plant functions. This integration of signals from the environment explains the synergistic effects of environmental inputs, such as the impact of nitrogen supply on plant response to elevated $\mathrm{CO}_{2}$ (see Tausz-Posch et al. 2020). For example, elevated $\mathrm{CO}_{2}$ concentrations induced decreases in the level and activity of nitrate reductase especially when nitrate supply was high (see above; Du et al. 2008, Bian et al. 2020). Conversely, limiting nitrogen supply can exacerbate the effects of elevated $\mathrm{CO}_{2}$ and high light supply. Limiting nitrogen supply strongly reduces plant sink activity and worsens source-sink imbalance (Paul and Driscoll 1997, Logan et al. 1999). Recent reports have, therefore, suggested that some level of nitrogen fertilization in natural plant communities (that are frequently nutrientlimited) may mitigate the negative effects of elevated $\mathrm{CO}_{2}$ in some scenarios (Wang et al. 2020). Furthermore, other environmental factors that lower plant sink activity and exacerbate plant source-sink balance will exacerbate metabolic disruption (Aranjuelo et al. 2005).

Maintenance of redox homeostasis in photosynthetic organisms: Plant source-sink imbalance is prevented by a high sink activity. When sink activity is high, sugar transporters (such as glucose 6-phosphate/phosphate translocator GPT2; Knappe et al. 2003) that export sugar from the chloroplast and play a role in metabolic adjustment may be upregulated in response to environmental change (Dyson et al. 2015). A backing up of electrons in the electron transport chain can be further counteracted by the routing of electron flow to alternative pathways, such as cyclic electron flow in the chloroplast (cyclic flow around
PSI and other pathways; Kramer et al. 2004, Ivanov et al. 2012, Blanco et al. 2013, Courteille et al. 2013, Strand et al. 2016). These alternative routes for electron flow also support dissipative pathways that remove excess absorbed light (excess excitation energy) as harmless heat (Kawashima et al. 2017). In addition to the chloroplast, mitochondria, as well as processes associated with the cell membrane, produce more oxidants under elevated $\mathrm{CO}_{2}$ concentrations, which requires coordinated adjustments across the cell to maintain cellular redox homeostasis (Foyer and Noctor 2020). Plant mitochondrial alternative oxidase $(\mathrm{AOX})$ is a key player in the coordination of alternative electron flow in mitochondria and chloroplasts (Yoshida et al. 2007, 2011; Vishwakarma et al. 2014, 2015; Shapiguzov et al. 2019). AOX serves as a safe outlet for electrons in the mitochondria and maintains cellular redox homeostasis when changes in the environment threaten to disrupt metabolism (Yoshida et al. 2007, Voss et al. 2013). Moreover, plant AOX levels responded to $\mathrm{CO}_{2}$ and light supply in the growth environment (Wang et al. 2014).

\section{Plant microbiome and plant productivity}

The plant microbiome - communities of bacteria, fungi, protozoa, archaea, and viruses (Mueller and Sachs 2015) is associated with various plant parts (Turner et al. 2013), including roots (Pieterse et al. 2016) and leaves (Marquez-Santacruz et al. 2010). The extent of plant response to the presence of microorganisms depends on environmental conditions (Becklin et al. 2016), such as $\mathrm{CO}_{2}$ concentration (see, e.g., Syvertsen and Graham 1999, Gavito et al. 2002, Jifon and Wolfe 2002) and nitrogen availability (see, e.g., Johnson et al. 2010, Weese et al. 2015).

In the following section, the available evidence is integrated into support of the potential of symbiotic relationships with microorganisms to enhance plant photosynthetic productivity by multiple mechanisms (Figs. 1, 5, and 6), including:

- provision of additional sinks for carbohydrates (Stefan et al. 2013, Ishizawa et al. 2017, Adams et al. 2018, Yamakawa et al. 2018);

- supply of nutrients that support the growth of sink tissues without disrupting nitrogen metabolism;

- production of regulators of plant metabolism and growth with an emphasis on restoration of redox homeostasis via, e.g., synthesis of plant hormones (Vacheron et al. 2013) and input into central signaling networks that control photosynthetic capacity and growth. Such regulation may specifically include buffering of departures from plant redox homeostasis when environmental conditions shift (see, e.g., de Sousa Leite and Monteiro 2019, Ortíz et al. 2020).

As stated above, the plant microbiome may be able to contribute to maintaining plant redox homeostasis both indirectly - by consuming photosynthetically produced sugars (acting as sugar sinks) and balancing plant nitrogen status - and directly by manipulation of electron flow routes (Figs. 5, 6). Evidence that symbiotic partners act as sugar sinks is seen in symbioses between photosynthetic 
and nonphotosynthetic partners (Grant et al. 2006, 2013), where starch is mobilized from the chloroplast at higher rates. Fig. 5 depicts the general role of carbohydrates produced in plant photosynthesis in supporting the metabolism and growth of not only the plant, but also its microbial partners, and lists multiple microbial inputs into plant metabolism. An important additional line of support for the ability of symbiotic partners to regulate photosynthesis, other aspects of metabolism, and redox homeostasis of their photosynthetic partners comes from obligate host-algal symbioses. Xiang et al. (2020) reported differential expression of genes associated with

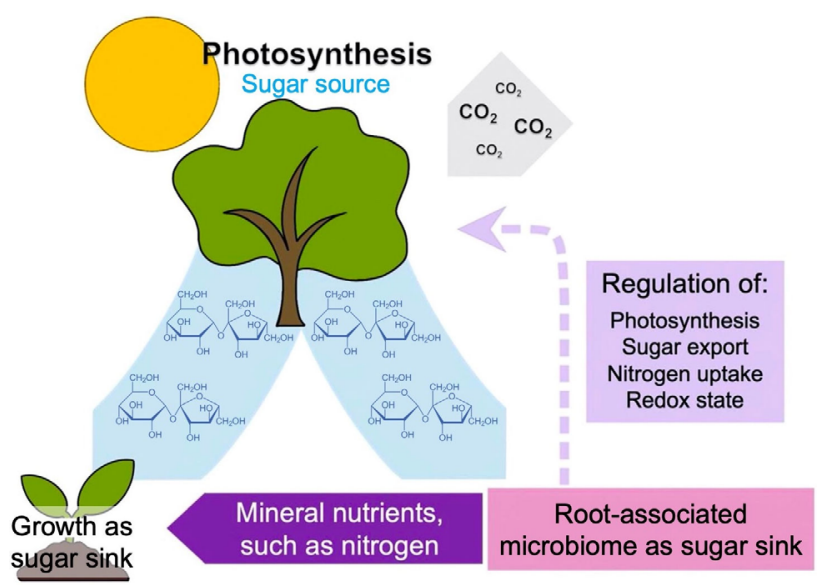

Fig. 5. Schematic depiction of the split flow of carbohydrate produced in photosynthesis (shown here as the transport form sucrose) to either the plant's own sinks (shown here as the growing tissues of the plant) or the root-associated microbiome that provides mineral nutrients to the plant as well as regulatory input into plant metabolism (purple box). nitrogen acquisition and assimilation in symbiotic algae growing within vs. outside of their nonphotosynthetic host, specifically algal genes for ammonium and nitrate transporters, nitrate reductase, and transporters for organic nitrogen compounds such as urea and purines. These same authors concluded that the symbiotic partners exhibited 'metabolic integration' between them, where nitrogen metabolism was 'decoupled' from photosynthesis in the photosynthetic partner in the sense that photosynthesis proceeded at high rates irrespective of nitrogen status by carbohydrate consumption by the nonphotosynthetic partner and associated relief of back-pressure into photosynthetic electron transport and prevention of excess ROS formation (Xiang et al. 2020). Moreover, interaction of the plant rhizosphere microbiome with the plant's AOX was reported by Ortíz et al. (2020). Fig. 6 summarizes common themes of how microorganisms provide multiple direct and indirect inputs into networks that regulate plant metabolism.

Such metabolic integration is reminiscent of the control of vital aspects of human functions by microbial gene regulators that target organellar electron transport chains and modulate the production of ROS (SaintGeorges-Chaumet et al. 2015, Ballard and Towarnicki 2020). Plants possess organellar electron transport chains in chloroplasts as well as in mitochondria, and both plant organelles may engage in chemical communication with microorganisms (Han et al. 2019, Yang et al. 2021). The ability of microorganisms to suppress the formation of ROS - that also participate in host defense against pathogens - presumably played a role in the evolution of host/microbe symbioses. This ability of microorganisms to manipulate the host redox state appears to have a key role in human and plant host health and/or productivity today (Yang et al. 2021). Conversely, such modulation of plant metabolism by beneficial microbial partners can also

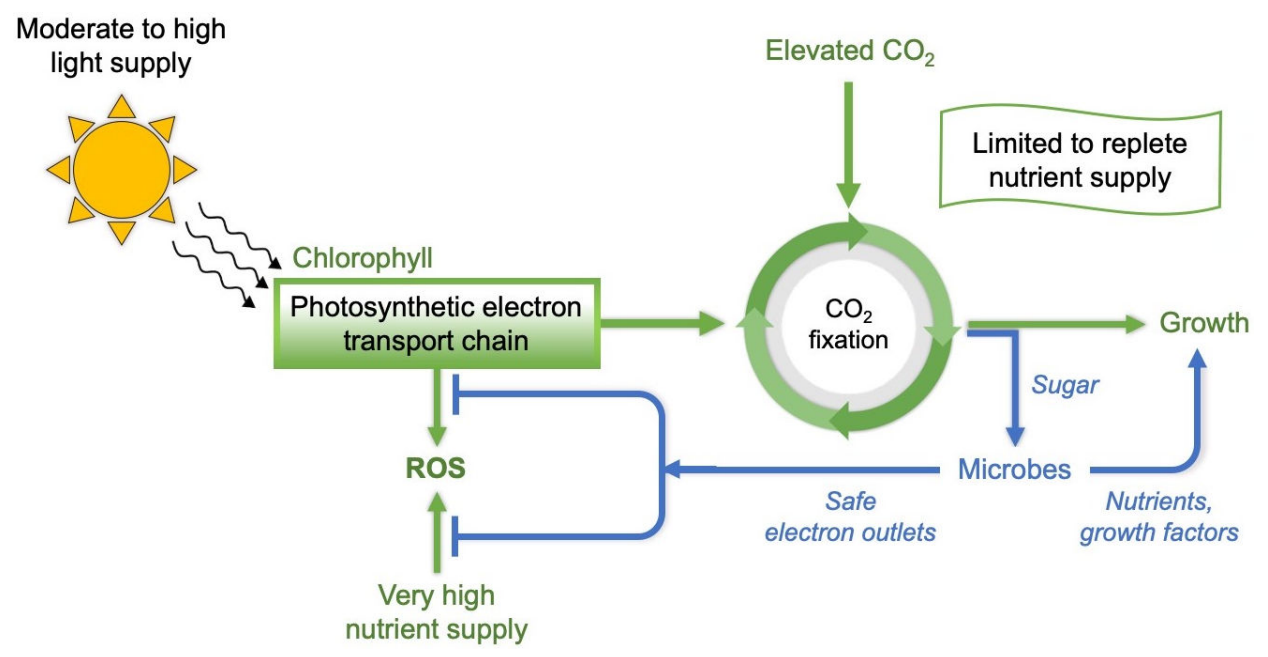

Fig. 6. Schematic depiction that summarizes the multiple ways in which the plant microbiome can support plant growth (blue arrows), i.e., by provision of nutrients and plant growth factors, acting as an additional or alternative sugar sink, and presumably also by inducing safe outlets for electrons, and preventing excess reactive oxygen (ROS) formation in photosynthetic electron transport as well as nitrogen metabolism under high nitrate supply (presumably by adjusting the ratio of nitrate-to-ammonium supply and utilization). 
augment plant defense against pathogens (Vandana et al. 2021) as well as participate in redox-mediated quorum sensing in plants and modeling of rhizosphere architecture (Fuller et al. 2017). For example, signaling molecules involved in quorum sensing have activity as plant gene regulators (Ohkama-Ohtsu and Wasaki 2010, Phour et al. 2020) in a way that is reminiscent of the gene-regulatory activity of gut microbial metabolites in animals, including regulation of host mitochondrial redox homeostasis (Saint-Georges-Chaumet et al. 2015). In addition to direct communication between microorganisms and plant organelles, the sugar consumption by microbial partners presumably provides input into the plant's intrinsic sourcesink regulatory networks.

Concerning the ability of plant-microbe interaction to elevate the plant's ability to maintain growth under abiotic stress, a recent study on the response of mustard (Brassica juncea) to drought conditions reported that inoculated $v s$. uninoculated plants exhibited enhanced shoot and root biomass, greater water content, higher photosynthetic rates, greater expression of antioxidant enzymes, and concluded that 'rhizobacteria mediated maintenance of ROS homeostasis' (cf. Figs. 5 and 6; Asha et al. 2021). Similar beneficial effects of rhizobacteria are also seen under other environmental stresses (Yang et al. 2009, Dhayalan and Karuppasamy 2021).

When plant sink tissues consume large amounts of sugar under conditions that are already favorable for plant growth, additional sugar consumption by microbial partners could hypothetically represent competition for sugar between the plant and its microbial partners. However, if the plant were able to enhance its photosynthetic capacity enough to fully accommodate the combined sugar demands, no competition should result. In other words, upregulation of photosynthetic capacity through the plant's existing regulatory supply-anddemand-based mechanisms should be able to produce enough additional sugar to prevent competition. While experimental manipulation of the plant microbiome is challenging in terrestrial plants growing in soil, some evidence is available for overall enhanced plant productivity in the presence of fungal partners of terrestrial plants (Romero-Munar et al. 2017, Yang et al. 2020). Inoculation of roots of terrestrial plants with arbuscular mycorrhizal fungi increased plant root volume and activity and triggered photosynthetic upregulation (Chen et al. 2017, Romero-Munar et al. 2017). Conversely, elimination of the mycorrhizal system of cucumber resulted in a decline in photosynthesis (Gavito et al. 2019; see also Lamhamedi et al. 1994). Transcriptomic analysis of such systems revealed differential gene expression in pathways of photosynthesis, hormone metabolism, carbohydrate metabolism, amino acid metabolism, stress response, signal transduction, and antioxidation (Yang et al. 2020), all of which are consistent with, and validate, the general framework summarized in Figs. 2, 5, and 6. There is also some evidence for increased growth of inoculated vs. sterile aquatic duckweed plants, which allow facile manipulation of the rhizosphere microbiome (Ishizawa et al. 2017, 2020; Toyama et al. 2017) that consisted mainly (80-95\%) of Proteobacteria (Acosta et al. 2020, Huang et al. 2020, Ishizawa et al. 2020, Rana et al. 2020).

However, more work is needed to understand plant interaction with microbial communities in specific environmental contexts. For example, inoculation of a sterile aquatic plant line (genus Lemna) with a bacterial strain widely reported to promote plant growth resulted in pronounced growth enhancement under some conditions but in growth penalties under other conditions - where the bacterium competed with the plant for mineral nutrients (Ishizawa et al. 2017, Khairina et al. 2021). Ishizawa et al. (2020) also reported both beneficial and adverse effects of microorganisms on duckweed growth, and future research is warranted to further elucidate the mechanisms of these interactions (for a review on the potential of duckweeds as a model system for research on plant-microbe interaction and other aspects of plant biology, see Acosta et al. 2021).

Conclusions: In response to combinations of elevated atmospheric $\mathrm{CO}_{2}$ and excess light, imbalances in plant source-sink ratio and redox state are addressed by the plant via downregulation of key photosynthetic genes, which results in reduced foliar protein content in $\mathrm{C}_{3}$ plants and a higher carbon-to-nitrogen ratio of plant biomass. Any additional stresses that curb growth, however, can trigger more pronounced photosynthetic downregulation, exacerbate growth penalties, and accelerate senescence. Microbial partners may be able to support plant productivity under challenging environmental conditions by providing nutrients, acting as an additional carbohydrate sink, and via direct manipulation of plant redox state. While the present review focused on a small set of selected abiotic factors, plant-microbe interaction also plays a critical role under numerous other abiotic conditions. These include conditions (such as heavy metal or saline stress) under which plant-microbe interactions play a critical role in plant tolerance as well for bioremediation (Fester et al. 2014, Islam et al. 2021). Moreover, future research is needed to integrate microbial services into the framework of plant interaction with not only the abiotic but also the biotic environment (Dodds et al. 2020).

\section{References}

Acosta K., Appenroth K.J., Borisjuk L. et al.: Return of the Lemnaceae: duckweed as a model plant system in the genomics and postgenomics era. - Plant Cell 33: 3207-3234. 2021.

Acosta K., Xu J., Gilbert S. et al.: Duckweed hosts a taxonomically similar bacterial assemblage as the terrestrial leaf microbiome. - PLoS ONE 15: e0228560, 2020.

Adams W.W. III, Muller O., Cohu C.M., Demmig-Adams B.: May photoinhibition be a consequence, rather than a cause, of limited plant productivity? - Photosynth. Res. 117: 31-44, 2013.

Adams W.W. III, Muller O., Cohu C.M., Demmig-Adams B.: Photosystem II efficiency and non-photochemical quenching in the context of source-sink balance. - In: Demmig-Adams B., Garab G., Adams W.W. III, Govindjee (ed.): NonPhotochemical Quenching and Energy Dissipation in Plants, 
Algae and Cyanobacteria. Advances in Photosynthesis and Respiration. Pp. 503-529. Springer, Dordrecht 2014.

Adams W.W. III, Stewart J.J., Demmig-Adams B.: Photosynthetic modulation in response to plant activity and the environment. - In: Adams W.W. III, Terashima I. (ed.): The Leaf: A Platform for Performing Photosynthesis. Advances in Photosynthesis and Respiration. Pp. 493-563. Springer, Dordrecht 2018.

Adams W.W. III, Zarter C.R., Mueh K.E. et al.: Energy dissipation and photoinhibition: a continuum of photoprotection. - In: Demmig-Adams B., Adams W.W. III, Mattoo A.K. (ed.): Photoprotection, Photoinhibition, Gene Regulation, and Environment. Advances in Photosynthesis and Respiration. Pp. 49-64. Springer, Dordrecht 2006.

Adavi S.B., Sathee L.: Elevated $\mathrm{CO}_{2}$ alters tissue balance of nitrogen metabolism and downregulates nitrogen assimilation and signalling gene expression in wheat seedlings receiving high nitrate supply. - Protoplasma 258: 219-233, 2021a.

Adavi S.B., Sathee L.: Elevated $\mathrm{CO}_{2}$ differentially regulates root nitrate transporter kinetics in a genotype and nitrate dosedependent manner. - Plant Sci. 305: 110807, 2021 b.

Agüera E., De la Haba P.: Leaf senescence in response to elevated atmospheric $\mathrm{CO}_{2}$ concentration and low nitrogen supply. Biol. Plantarum 62: 401-408, 2018

Ainsworth E.A., Long S.P.: 30 years of free-air carbon dioxide enrichment (FACE): What have we learned about future crop productivity and its potential for adaptation? - Glob. Change Biol. 27: 27-49, 2021.

Ainsworth E.A., Rogers A., Nelson R., Long S.P.: Testing the "source-sink" hypothesis of down-regulation of photosynthesis in elevated $\left[\mathrm{CO}_{2}\right]$ in the field with single gene substitutions in Glycine max. - Agr. Forest Meteorol. 122: 85-94, 2004.

Andrade A., Wolfe D.W., Fereres E.: Leaf expansion, photosynthesis, and water relations of sunflower plants grown on compacted soil. - Plant Soil 149: 175-184, 1993.

Aranjuelo I., Ebbets A.L., Evans R.D. et al.: Maintenance of $\mathrm{C}$ sinks sustains enhanced $\mathrm{C}$ assimilation during long-term exposure to elevated $\left[\mathrm{CO}_{2}\right]$ in Mojave Desert shrubs. Oecologia 167: 339-354, 2011.

Aranjuelo I., Pérez P., Hernández L. et al:: The response of nodulated alfalfa to water supply, temperature and elevated $\mathrm{CO}_{2}$ : photosynthetic downregulation. - Physiol. Plantarum 123: 348-358, 2005.

Asha A.D., Nivetha N., Krishna G.K. et al.: Amelioration of short-term drought stress during different growth stages in Brassica juncea by rhizobacteria mediated maintenance of ROS homeostasis. - Physiol. Plantarum 172: 1880-1893, 2021.

Bahrami H., De Kok L.J., Armstrong R. et al.: The proportion of nitrate in leaf nitrogen, but not changes in root growth, are associated with decreased grain protein in wheat under elevated $\left[\mathrm{CO}_{2}\right]$. - J. Plant Physiol. 216: 44-51, 2017.

Ballard J.W.O., Towarnicki S.G.: Mitochondria, the gut microbiome and ROS. - Cell. Signal. 75: 109737, 2020.

Becklin K.M., Mullinix G.W.R., Ward J.K.: Host plant physiology and mycorrhizal functioning shift across a glacial through future $\left[\mathrm{CO}_{2}\right]$ gradient. - Plant Physiol. 172: 789-801, 2016.

Bian Z., Wang Y., Zhang X. et al.: A review of environment effects on nitrate accumulation in leafy vegetables grown in controlled environments. - Foods 9: 732, 2020.

Blanco N.E., Ceccoli R.D., Vía M.V.D. et al.: Expression of the minor isoform pea ferredoxin in tobacco alters photosynthetic electron partitioning and enhances cyclic electron flow. Plant Physiol. 161: 866-879, 2013.

Bloom A.J.: The increasing importance of distinguishing among plant nitrogen sources. - Curr. Opin. Plant Biol. 25: 10-16, 2015.

Burnett A.C., Rogers A., Rees M., Osborne C.P.: Nutrient sink limitation constrains growth in two barley species with contrasting growth strategies. - Plant Direct 2: e00094, 2018.

Busch F.A., Sage R.F., Farquhar G.D.: Plants increase $\mathrm{CO}_{2}$ uptake by assimilating nitrogen via the photorespiratory pathway. Nat. Plants 4: 46-54, 2018.

Carlson-Nilsson U., Aloisi K., Vågen I.M. et al.: Trait expression and environmental responses of pea (Pisum sativum L.) genetic resources targeting cultivation in the Arctic. - Front. Plant Sci. 12: 688067, 2021.

Chaput V., Martin A., Lejay L., Doerner P.: Redox metabolism: The hidden player in carbon and nitrogen signaling? - J. Exp. Bot. 71: 3816-3826, 2020.

Chen J., Zhang H., Zhang X., Tang M.: Arbuscular mycorrhizal symbiosis alleviates salt stress in black locust through improved photosynthesis, water status, and $\mathrm{K}^{+} / \mathrm{Na}^{+}$ homeostasis. - Front. Plant Sci. 8: 1739, 2017.

Chouhan G.K., Verma J.P., Jaiswal D.K. et al.: Phytomicrobiome for promoting sustainable agriculture and food security: opportunities, challenges, and solutions. - Microbiol. Res. 248: 126763, 2021.

Courteille A., Vesa S., Sanz-Barrio R. et al.: Thioredoxin m4 controls photosynthetic alternative electron pathways in Arabidopsis. - Plant Physiol. 161: 508-520, 2013.

Dai N., Schaffer A., Petreikov M. et al.: Overexpression of Arabidopsis hexokinase in tomato plants inhibits growth, reduces photosynthesis, and induces rapid senescence. - Plant Cell 11: 1253-1266, 1999.

de Sousa Leite T., Monteiro F.A.: Partial replacement of nitrate by ammonium increases photosynthesis and reduces oxidative stress in tanzania guinea grass exposed to cadmium. - Ecotox. Environ. Safe. 174: 592-600, 2019.

Demmig-Adams B., Cohu C.M., Muller O., Adams W.W. III: Modulation of photosynthetic energy conversion efficiency in nature: from seconds to seasons. - Photosynth. Res. 113: 75-88, 2012.

Demmig-Adams B., Stewart J.J., Adams W.W. III: Photoprotection and the trade-off between abiotic and biotic defense. - In: Demmig-Adams B., Garab G., Adams W.W. III, Govindjee (ed.): Non-Photochemical Quenching and Energy Dissipation in Plants, Algae and Cyanobacteria. Advances in Photosynthesis and Respiration. Pp. 631-643. Springer, Dordrecht 2014

Demmig-Adams B., Stewart J.J., Adams W.W. III: Environmental regulation of intrinsic photosynthetic capacity: an integrated view. - Curr. Opin. Plant Biol. 37: 34-41, 2017.

Demmig-Adams B., Stewart J.J., Baker C.R., Adams W.W. III: Optimization of photosynthetic productivity in contrasting environments by regulons controlling plant form and function. - Int. J. Mol. Sci. 19: 872, 2018.

Dhayalan V., Karuppasamy S.: Plant growth promoting rhizobacteria in promoting sustainable agriculture. - Global J. Environ. Sci. Manage. 7: 1-18, 2021.

Diaz C., Purdy S., Christ A. et al.: Characterization of markers to determine the extent and variability of leaf senescence in Arabidopsis. A metabolic profiling approach. - Plant Physiol. 138: 898-908, 2005.

Dodds W.K., Zeglin L.H., Ramos R.J. et al.: Connections and feedback: Aquatic, plant, and soil microbiomes in heterogeneous and changing environments. - BioScience 70: 548-562, 2020.

Du S., Zhang Y., Lin X. et al.: Regulation of nitrate reductase by nitric oxide in Chinese cabbage pakchoi (Brassica chinensis L.). - Plant Cell Environ. 31: 195-204, 2008. 
Dusenge M.E., Duarte A.G., Way D.A.: Plant carbon metabolism and climate change: Elevated $\mathrm{CO}_{2}$ and temperature impacts on photosynthesis, photorespiration and respiration. - New Phytol. 221: 32-49, 2019.

Dyson B.C., Allwood J.W., Feil R. et al.: Acclimation of metabolism to light in Arabidopsis thaliana: the glucose 6-phosphate/phosphate translocator GPT2 directs metabolic acclimation. - Plant Cell Environ. 38: 1404-1417, 2015.

Feng Z., Rütting T., Pleijel H. et al.: Constraints to nitrogen acquisition of terrestrial plants under elevated $\mathrm{CO}_{2}$. - Glob. Change Biol. 21: 3152-3168, 2015.

Fester T., Giebler J., Wick L.Y. et al.: Plant-microbe interactions as drivers of ecosystem functions relevant for the biodegradation of organic contaminants. - Curr. Opin. Biotech. 27: 168-175, 2014

Foyer C.H.: Reactive oxygen species, oxidative signaling and the regulation of photosynthesis. - Environ. Exp. Bot. 154: 134142,2018

Foyer C.H., Noctor G.: Redox regulation in photosynthetic organisms: Signaling, acclimation, and practicalimplications.Antioxid. Redox Sign. 11: 861-905, 2009.

Foyer C.H., Noctor G.: Stress-triggered redox signalling: What's in pROSpect? - Plant Cell Environ. 39: 951-964, 2016.

Foyer C.H., Noctor G.: Redox homeostasis and signaling in a higher- $\mathrm{CO}_{2}$ world. - Annu. Rev. Plant Biol. 71: 157-182, 2020.

Fuller A.W., Young P., Pierce B.D. et al.: Redox-mediated quorum sensing in plants. - PLoS ONE 12: e0182655, 2017.

Gavito M.E., Bruhn D., Jakobsen I.: Phosphorus uptake by arbuscular mycorrhizal hyphae does not increase when the host plant grows under atmospheric $\mathrm{CO}_{2}$ enrichment. - New Phytol. 154: 751-760, 2002.

Gavito M.E., Jakobsen I., Mikkelsen T.N., Mora F.: Direct evidence for modulation of photosynthesis by an arbuscular mycorrhiza-induced carbon sink strength. - New Phytol. 223: 896-907, 2019.

Gill T.P.: The global epidemic of obesity. - Asia Pac. J. Clin. Nutr. 8: 75-81, 1999.

Grant A., People J., Rémond M. et al.: How a host cell signalling molecule modifies carbon metabolism in symbionts of the coral Plesiastrea versipora. - FEBS J. 280: 2085-2096, 2013.

Grant A., Rémond M., Starke-Peterkovic T., Hinde R.: A cell signal from the coral Plesiastrea versipora reduces starch synthesis in its symbiotic alga, Symbiodinium sp. - Comp. Biochem. Physiol. A 144: 458-463, 2006.

Han B., Lin C.C.J., Hu G., Wang M.C.: 'Inside Out'- a dialogue between mitochondria and bacteria. - FEBS J. 286: 630-641, 2019.

Hasanuzzaman M., Bhuyan M.H.M.B., Parvin K. et al.: Regulation of ROS metabolism in plants under environmental stress: A review of recent experimental evidence. - Int. J. Mol. Sci. 21: 8695, 2020.

Havaux M., García-Plazaola J.I.: Beyond non-photochemical fluorescence quenching: the overlapping antioxidant functions of zeaxanthin and tocopherols. - In: DemmigAdams B., Garab G., Adams W.W. III, Govindjee (ed.): Non-Photochemical Quenching and Energy Dissipation in Plants, Algae and Cyanobacteria. Advances in Photosynthesis and Respiration. Pp. 583-603. Springer, Dordrecht 2014.

Hu Y., Fan L., Liu Z. et al.: Rice production and climate change in Northeast China: Evidence of adaptation through land use shifts. - Environ. Res. Lett. 14: 024014, 2019.

Huang W., Gilbert S., Poulev A. et al.: Host-specific and tissuedependent orchestration of microbiome community structure in traditional rice paddy ecosystems. - Plant Soil 452: 379395,2020 .
Ishizawa H., Kuroda M., Inoue D. et al.: Community dynamics of duckweed-associated bacteria upon inoculation of plant growth-promoting bacteria. - FEMS Microbiol. Ecol. 96: fiaa101, 2020

Ishizawa H., Kuroda M., Morikawa M., Ike M.: Evaluation of environmental bacterial communities as a factor affecting the growth of duckweed Lemna minor. - Biotechnol. Biofuels 10: 62, 2017.

Islam M.S., Kormoker T., Idris A.M. et al.: Plant-microbe-metal interactions for heavy metal bioremediation: A review. - Crop Pasture Sci., 2021. (In print)

Ivanov A.G., Rosso D., Savitch L.V. et al:: Implications of alternative electron sinks in increased resistance of PSII and PSI photochemistry to high light stress in cold-acclimated Arabidopsis thaliana. - Photosynth. Res. 113: 191-206, 2012.

Jifon J.L., Wolfe D.W.: Photosynthetic acclimation to elevated $\mathrm{CO}_{2}$ in Phaseolus vulgaris L. is altered by growth response to nitrogen supply. - Glob. Change Biol. 8: 1018-1027, 2002.

Johnson N.C., Wilson G.W.T., Bowker M.A. et al.: Resource limitation is a driver of local adaptation in mycorrhizal symbioses. - P. Natl. Acad. Sci. USA 107: 2093-2098, 2010.

Kasai M.: Regulation of leaf photosynthetic rate correlating with leaf carbohydrate status and activation state of Rubisco under a variety of photosynthetic source/sink balances. - Physiol. Plantarum 134: 216-226, 2008.

Kawashima R., Sato R., Harada K., Masuda S.: Relative contributions of PGR5- and NDH-dependent photosystem I cyclic electron flow in the generation of a proton gradient in Arabidopsis chloroplasts. - Planta 246: 1045-1050, 2017.

Khairina Y., Jog R., Boonmak C. et al.: Indigenous bacteria, an excellent reservoir of functional plant growth promoters for enhancing duckweed biomass yield on site. - Chemosphere 268: 129247, 2021

Kilb B., Wietoska H., Godde D.: Changes in the expression of photosynthetic genes precede loss of photosynthetic activities and chlorophyll when glucose is supplied to mature spinach leaves. - Plant Sci. 115: 225-235, 1996.

Kim M.J., Ciani S., Schachtman D.P.: A peroxidase contributes to ROS production during Arabidopsis root response to potassium deficiency. - Mol. Plant 3: 420-427, 2010.

Knappe S., Flügge U.-I., Fischer K.: Analysis of the plastidic phosphate translocator gene family in Arabidopsis and identification of new phosphate translocator-homologous transporters, classified by their putative substrate-binding site. - Plant Physiol. 131: 1178-1190, 2003.

Kramer D.M., Avenson T.J., Edwards G.E.: Dynamic flexibility in the light reactions of photosynthesis governed by both electron and proton transfer reactions. - Trends Plant Sci. 9: 349-357, 2004.

Krapp A., Stitt M.: An evaluation of direct and indirect mechanisms for the "sink-regulation" of photosynthesis in spinach: Changes in gas exchange, carbohydrates, metabolites, enzyme activities and steady-state transcript levels after coldgirdling source leaves. - Planta 195: 313-323, 1995.

Krasensky-Wrzaczek J., Kangasjärvi J.: The role of reactive oxygen species in the integration of temperature and light signals. - J. Exp. Bot. 69: 3347-3358, 2018.

Lake J.A., Woodward F.I., Quick W.P.: Long-distance $\mathrm{CO}_{2}$ signalling in plants. - J. Exp. Bot. 53: 183-193, 2002.

Lamhamedi M.S., Godbout C., Fortin J.A.: Dependence of Laccaria bicolor basidiome development on current photosynthesis of Pinus strobus seedlings. - Can. J. Forest Res. 24: 1797-1804, 1994.

Li P., Ainsworth E.A., Leakey A.D.B. et al.: Arabidopsis transcript and metabolite profiles: ecotype-specific responses to open-air elevated $\left[\mathrm{CO}_{2}\right]$. - Plant Cell Environ. 31: 1673- 


\section{B. DEMMIG-ADAMS et al.}

1687, 2008.

Logan B.A., Demmig-Adams B., Rosenstiel T.N., Adams W.W. III: Effect of nitrogen limitation on foliar antioxidants in relationship to other metabolic characteristics. - Planta 209: 213-220, 1999.

Macabuhay A., Houshmandfar A., Nuttall J. et al.: Can elevated $\mathrm{CO}_{2}$ buffer the effects of heat waves on wheat in a dryland cropping system? - Environ. Exp. Bot. 155: 578-588, 2018.

Marquez-Santacruz H.A., Hernandez-Leon R., OrozcoMosqueda M.C. et al.: Diversity of bacterial endophytes in roots of Mexican husk tomato plants (Physalis ixocarpa) and their detection in the rhizosphere. - Genet. Mol. Res. 9: 23722380, 2010.

Mhamdi A., Noctor G.: High $\mathrm{CO}_{2}$ primes plant biotic stress defences through redox-linked pathways. - Plant Physiol. 172: 929-942, 2016.

Mølmann J.A.B., Dalmannsdottir S., Hykkerud A.L. et al.: Influence of Arctic light conditions on crop production and quality. - Physiol. Plantarum 172: 1931-1940, 2021.

Moore B.D., Cheng S., Sims D., Seemann J.R.: The biochemical and molecular basis for photosynthetic acclimation to elevated atmospheric $\mathrm{CO}_{2}$. - Plant Cell Environ. 22: 567-582, 1999.

Mueller U.G., Sachs J.L.: Engineering microbiomes to improve plant and animal health. - Trends Microbiol. 23: 606-617, 2015.

Ohkama-Ohtsu N., Wasaki J.: Recent progress in plant nutrition research: Cross-talk between nutrients, plant physiology and soil microorganisms. - Plant Cell Physiol. 51: 1255-1264, 2010.

Ortíz J., Sanhueza C., Romero-Munar A. et al.: In vivo metabolic regulation of alternative oxidase under nutrient deficiency interaction with arbuscular mycorrhizal fungi and Rhizobium bacteria. - Int. J. Mol. Sci. 21: 4201, 2020.

Padhan B.K., Sathee L., Meena H.S. et al.: $\mathrm{CO}_{2}$ elevation accelerates phenology and alters carbon/nitrogen metabolism vis-à-vis ROS abundance in bread wheat. - Front. Plant Sci. 11: $1061,2020$.

Paul M.J., Driscoll S.P.: Sugar repression of photosynthesis: The role of carbohydrates in signalling nitrogen deficiency through source:sink imbalance. - Plant Cell Environ. 20: 110-116, 1997.

Paul M.J., Foyer C.H.: Sink regulation of photosynthesis. J. Exp. Bot. 52: 1383-1400, 2001.

Phour M., Sehrawat A., Sindhu S.S., Glick B.R.: Interkingdom signaling in plant-rhizomicrobiome interactions for sustainable agriculture. - Microbiol. Res. 241: 126589, 2020.

Pieterse C.M.J., de Jonge R., Berendsen R.L.: The soil-borne supremacy. - Trends Plant Sci. 21: 171-173, 2016.

Poorter H., Bühler J., van Dusschoten D. et al.: Pot size matters: a meta-analysis of the effects of rooting volume on plant growth. - Funct. Plant Biol. 39: 839-850, 2012.

Poorter H., Remkes C., Lambers H.: Carbon and nitrogen economy of 24 wild species differing in relative growth rate. - Plant Physiol. 94: 621-627, 1990.

Porras M.E., Lorenzo P., Medrano E. et al.: Photosynthetic acclimation to elevated $\mathrm{CO}_{2}$ concentration in a sweet pepper (Capsicum annuum) crop under Mediterranean greenhouse conditions: influence of the nitrogen source and salinity. Funct. Plant Biol. 44: 573-586, 2017.

Prins A., Kunert K., Foyer C.H.: Atmospheric $\mathrm{CO}_{2}$ signalling, cellular redox state and plant growth and development. In: Foyer C.H., Faragher R., Thornalley P. (ed.): Redox Metabolism and Longevity Relationships in Animals and Plants. Pp. 203-226. Taylor \& Francis, London 2009.

Queval G., Issakidis-Bourguet E., Hoeberichts F.A. et al.: Conditional oxidative stress responses in the Arabidopsis photorespiratory mutant cat 2 demonstrate that redox state is a key modulator of daylength-dependent gene expression, and define photoperiod as a crucial factor in the regulation of $\mathrm{H}_{2} \mathrm{O}_{2}$-induced cell death. - Plant J. 52: 640-657, 2007.

Rana K.L., Kour D., Kaur T. et al.: Endophytic microbes: Biodiversity, plant growth-promoting mechanisms and potential applications for agricultural sustainability. - Antonie van Leeuwenhoek 113: 1075-1107, 2020.

Romero-Munar A., Del-Saz N.F., Ribas-Carbó M. et al.: Arbuscular mycorrhizal symbiosis with Arundo donax decreases root respiration and increases both photosynthesis and plant biomass accumulation. - Plant Cell Environ. 40: 1115-1126, 2017.

Roth M.S., Westcott D.J., Iwai M., Niyogi K.K.: Hexokinase is necessary for glucose-mediated photosynthesis repression and lipid accumulation in a green alga. - Commun. Biol. 2: $347,2019$.

Saint-Georges-Chaumet Y., Attaf D., Pelletier E., Edeas M.: Targeting microbiota-mitochondria inter-talk: Microbiota control mitochondria metabolism. - Cell. Mol. Biol. 61: 121$124,2015$.

Sardans J., Rivas-Ubach A., Peñuelas J.: The C:N:P stoichiometry of organisms and ecosystems in a changing world: a review and perspectives. - Perspect. Plant Ecol. Evol. Syst. 14: 3347, 2012.

Shapiguzov A., Vainonen J.P., Hunter K. et al.: Arabidopsis RCD1 coordinates chloroplast and mitochondrial functions through interaction with ANAC transcription factors. - eLife 8: e43284, 2019.

Shin R., Schachtman D.P.: Hydrogen peroxide mediates plant root cell response to nutrient deprivation. - P. Natl. Acad. Sci. USA 101: 8827-8832, 2004.

Stefan M., Munteanu N., Stoleru V. et al.: Seed inoculation with plant growth promoting rhizobacteria enhances photosynthesis and yield of runner bean (Phaseolus coccineus L.).Sci. Hortic.-Amsterdam 151: 22-29, 2013.

Stitt M., Krapp A.: The interaction between elevated carbon dioxide and nitrogen nutrition: The physiological and molecular background. - Plant Cell Environ. 22: 583-621, 1999.

Strand D.D., Fisher N., Kramer D.M.: Distinct energetics and regulatory functions of the two major cyclic electron flow pathways in chloroplasts. - In: Kirchhoff H. (ed.): Chloroplasts: Current Research and Future Trends. Pp. 89100. Caister Academic Press, Norfolk 2016.

Suzuki N., Koussevitzky S., Mittler R., Miller G.: ROS and redox signalling in the response of plants to abiotic stress. Plant Cell Environ. 35: 259-270, 2012.

Syvertsen J.P., Graham J.H.: Phosphorus supply and arbuscular mycorrhizas increase growth and net gas exchange responses of two Citrus spp. grown at elevated $\left[\mathrm{CO}_{2}\right]$. - Plant Soil 208: 209-219, 1999.

Tausz-Posch S., Tausz M., Bourgault M.: Elevated $\left[\mathrm{CO}_{2}\right]$ effects on crops: advances in understanding acclimation, nitrogen dynamics and interactions with drought and other organisms. Plant Biol. 22: 38-51, 2020.

Thomas R.B., Strain B.R.: Root restriction as a factor in photosynthetic acclimation of cotton seedlings grown in elevated carbon dioxide. - Plant Physiol. 96: 627-634, 1991.

Toyama T., Kuroda M., Ogata Y. et al.: Enhanced biomass production of duckweeds by inoculating a plant growthpromoting bacterium, Acinetobacter calcoaceticus P23, in sterile medium and non-sterile environmental waters. - Water Sci. Technol. 76: 1418-1428, 2017.

Turner T.R., James E.K., Poole P.S.: The plant microbiome. Genome Biol. 14: 209, 2013. 
Vacheron J., Desbrosses G., Bouffaud M.-L. et al.: Plant growthpromoting rhizobacteria and root system functioning. - Front. Plant Sci. 4: 356, 2013.

Vandana U.K., Rajkumari J., Singha L.P. et al.: The endophytic microbiome as a hotspot of synergistic interactions, with prospects of plant growth promotion. - Biology 10: 101, 2021.

Vishwakarma A., Bashyam L., Senthilkumaran B. et al.: Physiological role of AOX1a in photosynthesis and maintenance of cellular redox homeostasis under high light in Arabidopsis thaliana. - Plant Physiol. Bioch. 81: 44-53, 2014.

Vishwakarma A., Tetali S.D., Selinski J. et al.: Importance of the alternative oxidase (AOX) pathway in regulating cellular redox and ROS homeostasis to optimize photosynthesis during restriction of the cytochrome oxidase pathway in Arabidopsis thaliana. - Ann. Bot.-London 116: 555-569, 2015.

Vitt P., Havens K., Kramer A.T. et al.: Assisted migration of plants: Changes in latitudes, changes in attitudes. - Biol. Conserv. 143: 18-27, 2010.

Voss I., Sunil B., Scheibe R., Raghavendra A.S.: Emerging concept for the role of photorespiration as an important part of abiotic stress response. - Plant Biol. 15: 713-722, 2013.

Wang H., Zhou G.S., Jiang Y.L. et al.: Photosynthetic acclimation and leaf traits of Stipa bungeana in response to elevated $\mathrm{CO}_{2}$ under five different watering conditions. - Photosynthetica 55: 164-175, 2017.

Wang J., Cheung M., Rasooli L. et al.: Plant respiration in a high $\mathrm{CO}_{2}$ world: How will alternative oxidase respond to future atmospheric and climatic conditions? - Can. J. Plant Sci. 94: 1091-1101, 2014.

Wang S., Zhang Y., Ju W. et al.: Recent global decline of $\mathrm{CO}_{2}$ fertilization effects on vegetation photosynthesis. - Science 370: 1295-1300, 2020.

Weese D.J., Heath K.D., Dentinger B.T.M., Lau J.A.: Long-term nitrogen addition causes the evolution of less-cooperative mutualists. - Evolution 69: 631-642, 2015.
Wilson K.E., Ivanov A.G., Öquist G. et al.: Energy balance, organellar redox status, and acclimation to environmental stress. - Can. J. Bot. 84: 1355-1370, 2006.

Wu F., Sun X., Hu X. et al.: Response of nitrogen metabolism in masson pine needles to elevated $\mathrm{CO}_{2}$. - Forests 11: 390, 2020.

Xiang T., Lehnert E., Jinkerson R.E. et al.: Symbiont population control by host-symbiont metabolic interaction in Symbiodiniaceae-cnidarian associations. - Nat. Commun. 11: 108, 2020.

Yamakawa Y., Jog R., Morikawa M.: Effects of co-inoculation of two different plant growth-promoting bacteria on duckweed. - Plant Growth Regul. 86: 287-296, 2018.

Yang F., Xiao K., Pan H., Liu J.: Chloroplast: the emerging battlefield in plant-microbe interactions. - Front. Plant Sci. 12: 637853, 2021.

Yang J., Kloepper J.W., Ryu C.-M.: Rhizosphere bacteria help plants tolerate abiotic stress. - Trends Plant Sci. 14: 1-4, 2009.

Yang Y., Guo Y., Zhong J. et al.: Root physiological traits and transcriptome analyses reveal that root zone water retention confers drought tolerance to Opisthopappus taihangensis. Sci. Rep.-UK 10: 2627, 2020.

Yilmaz O., Kahraman K., Ozturk L.: Elevated carbon dioxide exacerbates adverse effects of $\mathrm{Mg}$ deficiency in durum wheat. - Plant Soil 410: 41-50, 2017.

Yoshida K., Terashima I., Noguchi K.: Up-regulation of mitochondrial alternative oxidase concomitant with chloroplast over-reduction by excess light. - Plant Cell Physiol. 48: 606614, 2007.

Yoshida K., Watanabe C.K., Terashima I., Noguchi K.: Physiological impact of mitochondrial alternative oxidase on photosynthesis and growth in Arabidopsis thaliana. - Plant Cell Environ. 34: 1890-1899, 2011.

Zaffagnini M., Fermani S., Marchand C.H. et al.: Redox homeostasis in photosynthetic organisms: novel and established thiol-based molecular mechanisms. - Antioxid. Redox Sign. 31: 155-210, 2019.

(C) The authors. This is an open access article distributed under the terms of the Creative Commons BY-NC-ND Licence. 